\title{
NUEVAS APARICIONES O LA HETERODOXIA DENTRO DE LA HETERODOXIA
}

\author{
Josefina Roma \\ UNIVERSITAT DE BARCELONA
}

Parece como si las heterodoxias tuvieran que estar mejor preparadas para la crítica interna y prevenidas contra el poder abusivo sobre las conciencias y el pensamiento de sus miembros, pero no es asf. De hecho aceptan la compañfa de otras heterodoxias mientras su estabilidad no está asegurada en ningún campo pero cuando existe el más mínimo punto de apoyo, la nueva ortodoxia parcial utiliza todo su poder coercitivo y de disuasión para expulsar de su seno cualquier amago de disidencia.

Este hecho, de eterno retorno en la rueda de la ortodoxia, podemos observarlo en gran cantidad de campos del poder. Especialmente interesante me parece en el terreno de las luchas entre la jerarquía eclesiástica y los movimientos aparicionistas de estos últimos años.

Voy a reflexionar sobre dos apariciones concretas que tuvieron grandes problemas con el obispado y que a su vez generaron cismas en su interior. Las relaciones entre la nueva ortodoxia y su heterodoxia correspondiente pueden servimos de modelo para un prototipo de relaciones de poder.

La primera aparición corresponde a la ermita del Remei en St. Vicenç dels Horts en el Baix Llobregat y la segunda, a un desarrollo posterior de Can Cerda, en Cerdanyola, Vallès Occidental.

Vamos a repasar a vuelapluma los rasgos más importantes de ambos centros.

El Remei era una ermita tradicional enclavada en una propiedad privada y a la que acudían en romería los pueblos de alrededor: Cervelló, Sta. Coloma de Cervelló, La Palma de Cervelló, Torrelles, etc.

St. Vicenç dels Horts, como le había ocurrido a la vecina población de l'Ordal hace más de dos siglos, tuvo sus enfrentamientos religiosos. En esta segunda, los enfrentamientos fueron debidos a la existencia de focos jansenistas. Asf́ mismo, a finales de los años sesenta, ambas poblaciones participaron en una oleada de integrismo religioso centrada en el grupo de El Palmar de Troya. De hecho, Clemente (el "papa" del Palmar), estuvo al comienzo de su actividad en St. Vicenç e hizo proselitismo entre varias familias importantes de la zona, que se arruinaron debido a las cuantiosas donaciones que hicieron a El Palmar. Con este dinero, joyas e inversiones, cree la gente de St. Vicenç que se empezó a financiar El Palmar.

Ha perdurado hasta nuestros días un grupo de seguidores de El Palmar, pero a finales de los 60 y principios de los 70 gozaban de una influencia popular que les permitía organizar viajes colectivos al lugar del Lentisco o Palmar.

En uno de estos viajes, cuenta que un poco para divertirse, había ido José Casasampere, el vidente de St. Vicenç. Era un joven tractorista, juerguista y alegre, pero volvió de su viaje cambiado y poco a poco empezó a sentirse llamado por las apariciones de la Virgen. Por otra parte, un vidente andaluz, Antonio Ruiz, también procedente de las primeras apariciones de El Palmar, a las que había acudido también en broma, vino a Barcelona con una misión concreta, la de encontrar un lugar donde la Virgen quería encontrarse con sus fieles.

Ambos videntes estuvieron buscando el lugar en que la Virgen iba a manifestarse, 
procediendo siempre del mismo modo, es decir, yendo a emplazamientos de ermitas tradicionales de los alrededores. Por fin, en el monte donde estaba la ermita del Remei, recibieron la visión de que habían llegado al lugar señalado.

En esta época empezaron los problemas de instalación del Santuario. De hecho, ya existía una ermita, pero las autoridades diocesanas privaron a los nuevos devotos de utilizarla. La ermita permanecía cerrada en sus peregrinaciones mensuales del día 5 , y en su puerta fijaron estampas 0 grabados de la Santa Faz (clara influencia palmarista), de San José, del P.Pío de Pietrelcina, e incluso de Fray Leopoldo, un capuchino granadino muerto en olor de santidad cuya veneración se había extendido a partir de la difusión de las apariciones andaluzas.

Aquellos fueron tiempos de investigación del obispado que tenía motivos para estar intranquilo por las quejas de los párrocos locales, que sufrían en sus propias demarcaciones la influencia de los fieles de El Palmar. Habia tenido lugar la gira de un sacerdote de procedencia incierta que celebraba la misa en casas particulares y que había tenido serios enfrentamientos con los párrocos. Incluso subió a Montserrat con un grupo de seguidores interfiriendo las celebraciones del monasterio con otras paralelas en el camarín de la Virgen.

El obispado en aquellos momentos pasaba por una etapa intermedia entre la descalificación total de los grupos aparicionistas, con un recuerdo muy claro de la ayuda que debía prestarle el poder civil para atajar estos "cismas" religiosos, y la actitud posterior de ignorar todo movimiento de este tipo para dejarle morir por sí mismo.

A finales de los años 60 y principio de los 70 estos grupos aparicionistas presentaban una cierta beligerancia, que después perdieron en estos lugares concretos pero que se conservo o renació en otros lugares, como Sarral en Catalunya, o Alcira en el Pais Valencià, por ejemplo.

Por lo tanto, las autoridades religiosas debfan tomar partido ante los requerimientos de sus párrocos que veían a aquellos grupos como elementos desestabiblizadores, en forma creciente, de sus comunidades a las que dirigían por la senda marcada por el Concilio Vaticano II.

En esta etapa postconciliar se sentían impotentes y decepcionados frente a una reacción integrista de manifestación popular. Sin embargo, seguían actuando administrativamente como en etapas anteriores, llamando a declarar a los protagonistas o pidiendo informes.

El Remei echó mano enseguida del consejo y dirección de dos teólogos jesuitas especializados en el tema de las apariciones por haber participado en la observación de otra muy importante, la de Pepita Pugès de Can Cerdà, en Cerdanyola. Ellos fueron los encargados de establecer un puente entre el obispado y el grupo de la aparición, no solamente aclarando la situación y tranquilizando a la jerarquía sino también, purificando la devoción que se estaba formando. Retiraron las estampas de Fray Leopoldo, puesto que al no estar canonizado no se podía rendirle culto públicamente. Algunas de las preces fueron suprimidas, como la parte de la letanía en la que se decía: "San José asunto al Cielo", dando un cariz cada vez más ortodoxo, al menos en apariencia, a toda la devoción. Este camino emprendido traería consecuencias muy importantes en la cohesión del grupo.

Antonio Ruiz, siguió en El Remei con José Casasampere hasta 1973. Los mensajes que recib́an eran básicamente los mismos y los seguidores de estas apariciones concretas les consideraban por un igual. Sin embargo, con el tiempo se fueron viendo ciertas diferencias entre ellos. Frente a José Casasampere que siguió la tendencia de concentrarse en el lugar sagrado, Antonio Ruiz seguía teniendo éxtasis en cualquier lugar, en lo alto de una escalera, conduciendo, etc. Los mensajes iniciales mandaban a los videntes a diversos lugares de apariciones, a conectar con todas ellas y sobretodo a El Palmar. Antonio Ruiz siguió estas conexiones, yendo de un lugar a otro, Monte Umbe, Ladeira, Garabandal, El Palmar. José se reduciría más tarde a El Remei, y sus peregrinaciones serían lugares ortodoxos, como Roma.

Frente al gran dinamismo presentado por estos grupos que contactaban con todos los videntes y enlazaban, en su justificación, a una serie determinada de apariciones, la influencia de la dirección de los dos jesuitas fue alejando cada vez más estas prácticas para evitar la 
procediendo siempre del mismo modo, es decir, yendo a emplazamientos de ermitas tradicionales de los alrededores. Por fin, en el monte donde estaba la ermita del Remei, recibieron la visión de que habían llegado al lugar señalado.

En esta época empezaron los problemas de instalación del Santuario. De hecho, ya existía una ermita, pero las autoridades diocesanas privaron a los nuevos devotos de utilizarla. La ermita permanecía cerrada en sus peregrinaciones mensuales del día 5 , y en su puerta fijaron estampas o grabados de la Santa Faz (clara influencia palmarista), de San José, del P.Pío de Pietrelcina, e incluso de Fray Leopoldo, un capuchino granadino muerto en olor de santidad cuya veneración se había extendido a partir de la difusión de las apariciones andaluzas.

Aquellos fueron tiempos de investigación del obispado que tenfa motivos para estar intranquilo por las quejas de los párrocos locales, que sufráan en sus propias demarcaciones la influencia de los fieles de El Palmar. Había tenido lugar la gira de un sacerdote de procedencia incierta que celebraba la misa en casas particulares y que hab́a tenido serios enfrentamientos con los párrocos. Incluso subió a Montserrat con un grupo de seguidores interfiriendo las celebraciones del monasterio con otras paralelas en el camarín de la Virgen.

El obispado en aquellos momentos pasaba por una etapa intermedia entre la descalificación total de los grupos aparicionistas, con un recuerdo muy claro de la ayuda que debla prestarle el poder civil para atajar estos "cismas" religiosos, y la actitud posterior de ignorar todo movimiento de este tipo para dejarle morir por sí mismo.

A finales de los años 60 y principio de los 70 estos grupos aparicionistas presentaban una cierta beligerancia, que después perdieron en estos lugares concretos pero que se conservo o renació en otros lugares, como Sarral en Catalunya, o Alcira en el Pais Valencià, por ejemplo.

Por lo tanto, las autoridades religiosas debfan tomar partido ante los requerimientos de sus párrocos que vefan a aquellos grupos como elementos desestabiblizadores, en forma creciente, de sus comunidades a las que dirigian por la senda marcada por el Concilio Vaticano II.

En esta etapa postconciliar se sentían impotentes y decepcionados frente a una reacción integrista de manifestación popular. Sin embargo, segúan actuando administrativamente como en etapas anteriores, llamando a declarar a los protagonistas o pidiendo informes.

El Remei echó mano enseguida del consejo y dirección de dos teólogos jesuitas especializados en el tema de las apariciones por haber participado en la observación de otra muy importante, la de Pepita Pugès de Can Cerda, en Cerdanyola. Ellos fueron los encargados de establecer un puente entre el obispado y el grupo de la aparición, no solamente aclarando la situación y tranquilizando a la jerarquía sino también, purificando la devoción que se estaba formando. Retiraron las estampas de Fray Leopoldo, puesto que al no estar canonizado no se podía rendirle culto públicamente. Algunas de las preces fueron suprimidas, como la parte de la letanía en la que se decía: "San José asunto al Cielo", dando un cariz cada vez más ortodoxo, al menos en apariencia, a toda la devoción. Este camino emprendido traería consecuencias muy importantes en la cohesión del grupo.

Antonio Ruiz, siguió en El Remei con José Casasampere hasta 1973. Los mensajes que recibfan eran básicamente los mismos y los seguidores de estas apariciones concretas les consideraban por un igual. Sin embargo, con el tiempo se fueron viendo ciertas diferencias entre ellos. Frente a José Casasampere que siguió la tendencia de concentrarse en el lugar sagrado, Antonio Ruiz seguía teniendo éxtasis en cualquier lugar, en lo alto de una escalera, conduciendo, etc. Los mensajes iniciales mandaban a los videntes a diversos lugares de apariciones, a conectar con todas ellas y sobretodo a El Palmar. Antonio Ruiz siguió estas conexiones, yendo de un lugar a otro, Monte Umbe, Ladeira, Garabandal, El Palmar. José se reduciría más tarde a El Remei, y sus peregrinaciones serían lugares ortodoxos, como Roma.

Frente al gran dinamismo presentado por estos grupos que contactaban con todos los videntes y enlazaban, en su justificación, a una serie determinada de apariciones, la influencia de la dirección de los dos jesuitas fue alejando cada vez más estas prácticas para evitar la 
contaminación de los videntes, puesto que con este contacto surgía una competitividad que enturbiaba la credibilidad y pureza del vidente.

En este momento, los mensajes de Antonio Ruiz empezaron a insistir sobre la unidad y sobre el descontento de la Virgen ante las críticas internas y las desconfianzas mutuas. Se hace referencia a la caridad con los hermanos y abundan frases como: "no juzguéis y no seréis juzgados".

Pronto surgirá una cuestión que separará a ambos videntes y que de hecho no es más que un pretexto que subraya una fisura que se había hecho definitiva.

De este modo se hacen patentes varias intervenciones atribuidas al demonio y que son justificadas, en principio, por la universalidad de sus intervenciones en lugares santos y con personas santas. José Casasampere sufre una agresión del demonio que intenta ahogarle, y también se le aparece una figura de Cristo, convenciéndole para que se sacara el escapulario, pero al pedirle que tire el crucifijo José le reconoce y acaba aquí su intervención.

Antonio Ruiz sufre una aparición del demonio en forma de la Virgen Maŕa. El demonio es reconocido al cabo de un rato. Pero las narraciones y justificaciones que se hacen de los hechos enfatizan la confusión e inseguridad que a partir de entonces empezó a sentir Antonio, siendo esta la causa de que la gente se alejara de él según las fuentes "ortodoxas" del Remei. Se sabe que hubo una pelea entre ambos videntes y se separaron.

Pero el verdadero cisma venía gestándose ante la diferente personalidad de sus apariciones. En el Remei se siguió con José Casasampere como único vidente, cuando en su primera época había tenido una justificación de la vidente andaluza María Martín, es decir cuando había contado con la intervención y apoyo de otros videntes y lugares de aparición.

Por otra parte, los sacerdotes directores recondujeron el fenómeno hacia contextos más ortodoxos y los separaron completamente de El Palmar e incluso pidieron a sus seguidores que no se acercaran al Santuario. Todo esto respondía al descrédito que iba cobrando El Palmar y al rechazo que inspiraba en el Obispado.

El Remei no ha llegado a reutilizar la ermita que ha quedado desbordada por los nuevos lugares de la Aparición y los dictados de la misma. Así, el grupo de fieles o Apóstoles, se ha encargado de la construcción de unas gradas detrás de una fuente, por ahora seca, puesto que la Virgen ha prometido que manará agua. Han hecho varias capillitas a $\mathrm{S}$. Francisco, al Nacimiento...Han plantado una cruz de tamaño natural, que la gente besa durante el ritual mensual, debido a estar enclavado en un lugar significativo de aparición. Han puesto una imagen de S. Miguel a la entrada y han ajardinado gran parte del camino. Alrededor de la explanada donde antes se reunían los romeros delante de la ermita, han dispuesto bancos. También han construido un Via Crucis cuyas estaciones han sido marcadas personalmente por la Virgen y por último, el lugar sagrado ha pasado de estar dentro de la ermita (hoy convertida en almacén del material de las peregrinaciones) a estar a un lado, un poco más en la cima del monte, en un lugar donde la Virgen se posó, y que han cubierto con un cristal que se besa de rodillas.

Detrás, a modo de nichos de cementerio, hay ahora una construcción con una reproducción de la Virgen de El Remei, titular de la ermita, la Santa Faz, Sta. María de Cervello, que hab́a vivido en una casa cercana hoy en el recinto del Santuario, y S. José. Másabajo hay un reclinatorio de piedra, donde se impone el velo de la Virgen a los enfermos.

La reconversión del paisaje se ha efectuado, junto con la llegada del camino hasta el Santuario, por un lugar donde antes sólo se podía ir a pie.

La nueva devoción y romería mensual del día 5, ampliada para el círculo de fieles de cada miércoles por la noche, ha sustituido a las antiguas romerías comarcales. Hoy día suelen fletarse varios autocares que llegan de las comarcas del Barcelonès y del Segrià.

Uno de los padres jesuitas ha seguido con la dirección de los rituales y con la interpretación y divulgación de los mensajes. También se ha constituido en Barcelona, bajo su dirección, una asociación de Hijas de María del Remei, que se reúnen para celebrar los primeros sábados. 
Por otra parte, el vidente José Casasampere, por encargo de la Virgen, ha fundado en St. Vicenç una residencia de ancianos desvalidos a los que cuida personalmente.

La impresión de burocratización es evidente en todos los campos y las plegarias se anotan en un papel impreso haciendo constar nombre y dirección de quien formula la petición.

Las apariciones públicas, aunque se dan, se han ido espaciando y cada vez se hace más rara la presencia del vidente en las romerías del día 5. El texto de los mensajes no es asequible al gran público y sólo circula entre los "apóstoles".

Esta es, grosso modo, la evolución del sector que se ha constituido en ortodoxia, con la cual aleja a quien no sigue sus directrices. La estratificación de los círculos de creyentes se hace evidente por las tareas, atribuciones e informaciones que comparten. Ello ha redundado últimamente en la disminución de público en las romerías del día 5 en relación a otras épocas en las que el contacto era directo y no se había formado esta barrera entre el poder de la información y los creyentes en general que, en la mayoría de las veces, solo reciben versiones de segunda mano.

En el otro extremo, el cisma de Antonio Ruiz se lleva tras de sí a un grupo de fieles y establece su lugar sagrado en otra ermita, bastante deteriorada, situada en Sta. María de Montcada. La ermita es la de Nuestra Señora del Turo, situada en una partida que aparece en los mensajes como "de los Pinos". La ermita data del s.XII y fue reconstruida en el s.XVIII gracias a la intervención de una religiosa de la Orden de las Dominicas de la Anunciata, aunque cuando fue reutilizada por el grupo de Antonio Ortiz estaba en bastante mal estado.

La actividad en este nuevo lugar sagrado dura, por lo menos, hasta 1976 y los mensajes de La Virgen insisten en que ha abandonado su presencia el lugar de El Remei y que se ha trasladado all, porque en el antiguo centro han dejado su pureza, se han separado del verdadero camino. Incluso llega a decir que alli fingen tener apariciones y prohibe a los fieles cismáticos volver a $\mathrm{El}$ Remei. También Cristo declara que Los Pinos es el único lugar de Cataluña donde se aparece. En alguno de los mensajes se especifica que todavía no ha levantado la prohibición de subir a El Remei.

En Los Pinos tienen lugar contactos directos, como la aparición de Cristo que le administra la Sagrada Forma a Antonio Ortiz de forma visible a todos. Es decir, sigue con todo el contacto directo posible, sin trabas ni alejamiento entre el vidente y los fieles.

Pero la búsqueda de la legalidad se hace evidente, pidiendo la Aparición que se restaure la capilla y se celebren misas en el recinto. Mientras, el grupo sigue viajando a lugares tradicionales en la devoción aceptada, como Montserrat. Esto es, intentando de algún modo, participar de la ortodoxia de cultos consolidados, acercándose a ellos con visiones y mensajes que verifican y aprueban esta identidad.

El esfuerzo de legitimación es constante aunque se mantiene la oposición al grupo originario al que despoja de todo contacto con la Aparición.

Finalmente, Antonio Ortiz, que había sido novicio en una orden religiosa, que posteriormente se había casado, que había recibido una gran influencia de Clemente de El Palmar (al que trata de justificar en sus visiones que declaran que ha sido calumniado e injustamente tratado) acaba por volver a El Palmar, desapareciendo de la escena de Montcada y de El Remei.

Los seguidores de El Remei no le recuerdan ya, excepto los del primer momento, que aseguran que se casó y que luego se fue a El Palmar, pero no he llegado a saber si confunden su anterior matrimonio o se trata de uno posterior.

En el segundo lugar de nuestra consideración, Can Cerdà, nos encontramos con una vidente única, Pepita Pugès, que tiene visiones desde su infancia, en cualquier lugar, pero que en algún momento situado a finales de los años 60 , la Virgen le insta a ir a un lugar que bendecirá particularmente. Esto es, pasa de sus visiones privadas a otras públicas en un lugar sagrado.

Ayudada por una familia protectora, esta vidente, de gran humildad de carácter, encuentra en el terreno de Can Cerdà el lugar indicado por La Virgen. Sobre un árbol caído, cerca de una fuente y frente a una explanada que linda con un restaurante, Pepita Pugès tiene sus visiones de La 
Virgen, lo que reunió desde el principio a gran cantidad de gente que pudo ver el fenómeno del sol girando y cambiando de colores.

El obispado nombró una comisión que examinó el caso e incluso llamó a la vidente para preguntarle sobre los puntos que podían hacer decidir a la jerarquía sobre la posibilidad del fenómeno. Como consecuencia de ello le prohibió volver al lugar de Can Cerdà, orden que Pepita cumplió pues era una persona sencilla y obediente que quería seguir dentro de la Iglesia.

$\mathrm{Ya}$ antes de su muerte aparecieron por el lugar videntes y curanderas intentando arrimarse al prestigio de las apariciones, pero fueron rechazadas por el grupo de fieles más inmediatos e influyentes, entre ellos, los que se encontraban como observadores de los jesuitas mencionados anteriormente. No se quería que las apariciones de Pepita perdieran credibilidad por la mezcla y participación de quienes podrían desprestigiarlas.

Después de su muerte, se fundó un patronato con un servicio de orden y con una organización de actividades tales como la publicación de un boletín mensual con todas las noticias referentes al santuario. Se fundó una casa para retiros y reuniones de seguidores y de jóvenes de Can Cerdà. En este campo se evolucionó mucho puesto que existe toda una organización con reuniones periódicas con una acción social para la formación de jóvenes, etc.

Por otra parte, las romerías mensuales, que se celebran cada día 11 congregan unos dos autocares de Barcelona y del barrio de Horta, más un número indeterminado de vehículos particulares que proceden de toda la provincia.

Sin embargo, la construcción de una capilla ha sido vetada por el obispado hasta hace dos años en que dio su consentimiento siempre que no coincidiera con el lugar exacto de las apariciones, pero la Administración Civil ha retrasado la ejecución del proyecto. El grupo de fieles responsables del santuario han edificado bien poco en todo este tiempo. Han rodeado con una cerca metálica todo el recinto, han construido una caseta cubierta para las velas y otra como depósito de material. Se colocó una imagen de piedra artificial de la Virgen de Lourdes, puesto que se aparecía con esta advocación, y la protegieron con una vitrina. El árbol sobre el que se aparecía, fue rápidamente convertido en reliquias que arrancaban los fieles y hoy subsiste sólo el tronco muerto.

El recinto y la romería mensual han atraído y producido gran cantidad de videntes de diversa importancia. Uno de estos casos es el de una mujer que obtuvo su curación en una de estas romerias y que fue entrando progresivamente en un proceso de videncia, primero en locuciones y más tarde, debido a una visita ordenada por La Virgen a El Escorial, en visiones que, en ciertos períodos, han llegado a ser diarias.

Esta vidente ha organizado gran cantidad de cenáculos de oración y acude con sus amigas y fieles a las romerías del día 11 .

Su actitud para con otros videntes de otras partes suele ser abierta, visitándoles con frecuencia y recibiendo cartas de unos y otros. También da conferencias por toda España acerca de los mensajes que ha recibido de la Virgen.

Si nos interesa citar este ejemplo es porque ha sido considerado como ortodoxo por la organización de Can Cerda. De hecho, sus visiones no tienen lugar en el Santuario. En cambio se ha originado una confrontación con otro grupo creado alrededor de otra vidente de Viladecans que proclama ser la continuadora de Pepita Pugès de la que a veces recibe mensajes.

Su curriculum venía avalado por un álbum de fotografías que recogian algunos fenómenos considerados extraordinarios que habían dejado constancia fotográfica, sistema éste ya comentado por mí en otra ocasión.

Esta nueva vidente intentó ser aceptada por la "ortodoxia" del Santuario pero no lo consiguió y se la echó con cierta violencia. En alguna ocasión se intentó incluso recurrir a la Guardia Civil para que la hiciera marchar, parece ser que en pleno éxtasis.

Cuando se la echo, sus seguidores y otros que se separaron del antiguo grupo siguieron celebrando sus romerías en otro momento de los días 11 , por la mañana y fuera del recinto vallado. De hecho han tenido problemas por estar siempre vigilados de modo que a veces deben cambiar 
el día de sus encuentros.

Esta vidente ofrece una vida de visiones desde la infancia, de modo parecido a Pepita Pugès, de la que había sido amiga personal, y se presenta con un trato directo. Los mensajes que transmite son de La Virgen y a veces de Pepita Pugès y los oyen directamente los devotos porque están junto a ella.

Sus mensajes insisten en presentarla no solo como continuadora de Pepita sino como la culminación de un proceso que La Virgen hubiera preparado.

Los seguidores de este orden nuevo atacan la ortodoxia de Can Cerdà culpándoles de haber utilizado mal los fondos de las aportaciones y también creen que otros videntes más "ortodoxos" están perdiendo su carisma porque no obedecen la voz de La Virgen, lo cual puede acarrearles grandes desgracias. En consecuencia exhortan a los demás a que recen por ellos porque se están alejando del camino.

Esta acusación de pérdida de fidelidad y pureza es rechazada con la violencia y la expulsión.

Como vemos, en ambos casos estudiados se produce una división similar. Grupos que han sido consolidados por su perduración, aunque no por su aprobación total de la jerarquía eclesiástica, pero sí con una cierta condescendencia, son celosos de sus privilegios y alejan de sí cualquier grupo nuevo o antiguo que se oponga a su imagen adquirida con tanto esfuerzo.

Por esto se alejan palmaristas y curanderos pero también cualquier nuevo intento de reconducir lo maravilloso en el Santuario.

Las normas establecidas rechazan a los disidentes con las mismas acusaciones, superchería, intervención del demonio, que en sus tiempos padecieron la clase de las heterodoxias primeras. El orgullo y la falta de obediencia a la jerarquía es substituido aqui por la falta de docilidad al proceso establecido por el poder del propio Santuario. No se admiten espontáneos que traten de apropiarse del prestigio adquirido.

Los disidentes enarbolan el arma del contacto directo y de la perversión y esclerosamiento de la antigua fuente, y aún de la posible desaparición del carisma otorgado por su infidelidad y contaminación. De esta manera, el grupo de fieles se desorienta, puesto que está ávido de maravillas y el distanciamiento progresivo de los videntes, ya sea por guardaespaldas, como en el caso de El Escorial, ya sea por su rara aparición, como en El Remei, desilusiona y enfría la relación.

Pero las armas de la "ortodoxia" no son menos certeras: el peligro de la intervención demoníaca llevaría a los fieles al punto diametralmente opuesto de donde quieren ir.

Si esto no es bastante convincente queda el recurso al poder "temporal" al que se reclama, como en el caso de las fundaciones de Magdalena Aulina de Banyoles, al hacerse la siguiente pregunta apenas terminada la Guerra Civil: "¿Tuvo conexiones el Bañolismo con el movimiento Rojo-Separatista?". Esta sola sospecha podía desencadenar una investigación por parte de las autoridades civiles de la época, y puestas en boca de los contrarios a la figura de Magdalena Aulina tenía casi el valor de una denuncia pública.

\section{BIBLIOGRAFIA}

BADONE, E.

1990 Religious Orthodoxy and Popular Faith in European society. Princeton.

CHENU, M.D.

1987 "Ortodoxia y heregía. El punto de vista del teólogo", a LE GOFF, J. Herejías y sociedades. 
HAMILTON, B.

1986 Religion in the Medieval West. Baltimore.

KIECKHEFER, $\mathbf{R}$.

$1984 \quad$ Unquiet Souls. Chicago.

SCHOLEM, G.

1987 "La metamorfosis del mesianismo herético de los sabbatianos", a LE GOFF, J., Herejlas y sociedades. 